\title{
Ultrasonic Measurement of Body Fat as a Means of Assessing Body Condition in Free-Ranging Raccoons (Procyon lotor)
}

\author{
Elizabeth M. Stringer, ${ }^{1}$ Michael K. Stoskopf, ${ }^{1}$ Theodore Simons, ${ }^{2}$ \\ Allan F. O'Connell, ${ }^{3}$ and Arielle Waldstein ${ }^{2}$ \\ ${ }^{1}$ Environmental Medicine Consortium, College of Veterinary Medicine, North Carolina State University, 4700 Hillsborough Street, \\ Raleigh, NC 27606, USA \\ ${ }^{2}$ USGS North Carolina Cooperative Fish and Wildlife Research Unit, Department of Biology, North Carolina State University, Raleigh, \\ NC 27695, USA \\ ${ }^{3}$ USGS Patuxent Wildlife Research Center, Beltsville Laboratory, 10300 Baltimore Avenue, Beltsville, MD 20705, USA
}

Correspondence should be addressed to Elizabeth M. Stringer, betsy_stringer@ncsu.edu

Received 27 July 2010; Accepted 18 October 2010

Academic Editor: W. D. Bowen

Copyright (c) 2010 Elizabeth M. Stringer et al. This is an open access article distributed under the Creative Commons Attribution License, which permits unrestricted use, distribution, and reproduction in any medium, provided the original work is properly cited.

\begin{abstract}
Assessment of body condition of free-ranging animals is important when evaluating population health and fitness. The following study used body condition scoring, ultrasound, and dissected physical measurement to assess fat stores in free-ranging raccoons (Procyon lotor). Measurements were taken of subcutaneous fat at interscapular, thoracolumbar, and lumbosacral paraspinal and ventral midline sites. These measurements were examined in relationship to body condition scores and body weight. The ultrasound technique accurately measured the subcutaneous fat of raccoons when compared to dissected physical measurement and yielded data that strongly correlated with both body condition score and body weight, with the ventral midline measurement most strongly correlated. This noninvasive method may be useful in conjunction with body condition score and body weight when assessing the nutritional status of raccoons and potentially other small carnivore species.
\end{abstract}

\section{Introduction}

Assessment of body composition of free-ranging animals provides a quantitative indication of nutritional status, health, and fitness of individuals or populations. More accurate methods for measuring markers of body composition improve our ability to assess relationships between body condition and survival [1] and provide better insight into population health.

Techniques developed to assess body condition include both direct and indirect measurements [2]. The use of direct methods, such as chemical analysis to determine whole-body composition, is often considered the standard to which other methods are compared [3]. Direct Analysis and Direct Method refer to the determination of total extracted lipid content of whole carcasses or more commonly tissue samples; this is accomplished by drying, pulverizing, and chemically extracting lipids with solvents [4]. Whole carcass direct analysis is often considered the most accurate means of assessing body composition [2], but the complexity of the extraction introduces opportunity for analytical error, and the technique is not applicable in many situations. The whole body Direct Method is expensive, time consuming and cannot be used to assess body condition of live animals $[1,5]$. Another direct method involves dissection and physical measurement of perivisceral or subcutaneous fat. This technique has been used to estimate fat content in nondomestic carnivores [6, 7].

Several indirect methods of estimating body condition do not require destruction of the animal. Morphometric condition indices, based on specific measurements of size and mass of individuals, are a commonly used indirect method [5]. Morphometrics vary between species and applications and include individual as well as composite measurements of various body parts including body, foot, carapace, or wing chord lengths and/or girth measurements 
[8]. The underlying assumption of these methods is that mass, once corrected for structural size, should reflect the relative condition of the animal [5]. However, discrepancies in interobserver measurements as well as variation in fat deposition can make these methods unreliable $[9,10]$.

Total body electrical conductivity (TOBEC) and bioimpedance analysis (BIA) are also indirect methods of body condition assessment. These are based on the principle that different tissues have different electrical properties and that an aggregate conductance can be related to overall body condition $[2,11,12]$. These methods have been used with some success to estimate body fat content in birds, small mammals, and pinnipeds $[1,5,13-17]$; however, results are variable. In validation studies using nondomestic species, neither BIA nor TOBEC accurately approximated fat levels obtained by Direct Analysis [17, 18]. Furthermore, accurate and repeatable BIA estimates require extensive training to standardize measurements [19].

Body condition scoring, another indirect means of measuring body condition, has become an integral part of assessing nutritional condition in veterinary patients. Body condition scoring is a subjective assessment of subcutaneous body fat stores, based on visual or tactile evaluation of muscle tone and key skeletal elements [20,21]. Scores are commonly based on a cardinal 5- or 9-point scale [21, 22]. Low scores represent animals with less body fat, and higher scores represent animals with more body fat. Standards for appropriate body condition score vary between animal species, and scoring is subjective based on individual evaluator experience [21]. The use of body condition scoring is widely used in veterinary medicine as an effective, inexpensive method for quantifying patient condition. This technique has been useful for assessing the degree of obesity in nondomestic carnivores [23], but relatively few reports exist in the wildlife literature $[18,23,24]$.

Imaging methods, including radiography, ultrasonography, computed tomography (CT), and magnetic resonance imaging (MRI), can also be used to evaluate body composition [3]. These methods have generally lacked portability, limiting their use to situations where animals can be transported for evaluation. The exception is ultrasonography. Modern ultrasound machines are lightweight, extremely portable, and battery-operated systems capable of complex imaging are available for use in the field. Ultrasound is now a widely used method for estimating body composition in domestic animals, and the techniques used in cattle and pigs have been validated extensively $[3,25,26]$. An ultrasound technique for measuring backfat thickness has been developed in dairy cattle and has been correlated to total body fat content [22]. This technique allows for evaluation of even slight changes in body condition [22]. Ultrasound has been used to successfully estimate body fat in moose (Alces alces) [27], elk (Cervus elaphus) [18], mule deer (Odocoileus hemionus) [28], and woodland caribou (Rangifer tarandus caribou) [29]. Ultrasound imaging has also been used to measure blubber thickness in pinnipeds [30-32], using biopsy measurements for validation [32].

Our study examines ultrasound measurement of fat and body condition scoring as potential markers of body

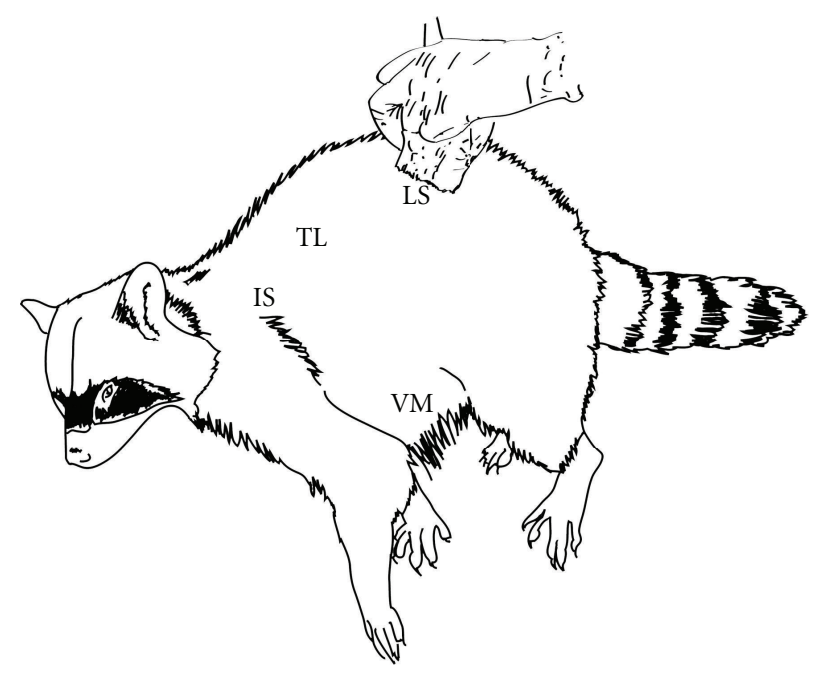

FIGURE 1: Diagram of ultrasound probe placement (IS = interscapular, $\mathrm{TL}=$ thoracolumbar, $\mathrm{LS}=$ lumbosacral, $\mathrm{VM}=$ ventral midline $)$.

condition in raccoons (Procyon lotor) using dissected physical fat depth measurements to validate ultrasound results.

\section{Methods}

Ultrasound measurements were obtained using a portable ultrasound machine (SonoSite Titan, SonoSite Inc., Bothell, WA 98021, USA) with a C60/5- $2 \mathrm{MHz}$ transducer. One individual operated the ultrasound machine and obtained all measurements throughout the study for consistency. To simulate field conditions, fur was not clipped but instead wet with isopropyl alcohol to provide good skin contact. Images of real-time ultrasound were paused to measure the depth of the combined epidermis, dermis, and subcutaneous fat layer to the nearest $0.01 \mathrm{~cm}$ using electronic internal calipers. Physical measurements of subcutaneous fat depth were taken through a skin incision using a ruler marked in millimeters.

A pilot study was performed on eight raccoons obtained from a rabies-monitoring program. All carcasses were frozen and thawed prior to measurements. Ultrasound and dissected physical measurements were taken at four locations using the above-described ultrasound technique. The four measured sites were selected for accessibility and expected repeatability of accurate probe placement based on palpable bony landmarks. Animals were placed in left lateral recumbency for the paraspinal measurements and dorsal recumbency for the ventral midline measurement. For the 3 paraspinal measurements (interscapular, thoracolumbar, and lumbosacral), the long axis of the transducer was placed parallel to the vertebral column, approximately $2-3 \mathrm{~cm}$ to the right of the dorsal spinal processes (see Figure 1 for probe orientation and placement). The interscapular paraspinal site was measured at the level of the scapular spine. The thoracolumbar paraspinal site was measured at the level of the last rib, and the lumbosacral paraspinal site was measured midway between the coxal tuber and ischial tuber. The ventral midline measurement was taken approximately 
Table 1: Medians and 90\% confidence intervals (in $\mathrm{cm}$ ) for the pilot study comparing two fat depth measurement techniques at four locations $(n=8)$.

\begin{tabular}{lcccc}
\hline & \multicolumn{2}{c}{ Ultrasound } & \multicolumn{2}{c}{ Ruler } \\
& Median & $90 \%$ CI & Median & $90 \%$ CI \\
\hline Interscapular & 0.31 & $0.26-0.36$ & 0.3 & $0.26-0.36$ \\
Thoracolumbar & 0.28 & $0.25-0.34$ & 0.2 & $0.2-0.27$ \\
Lumbosacral & 0.28 & $0.25-0.33$ & 0.2 & $0.18-0.27$ \\
Ventral midline & 0.28 & $0.26-0.32$ & 0.2 & $0.17-0.33$ \\
\hline
\end{tabular}

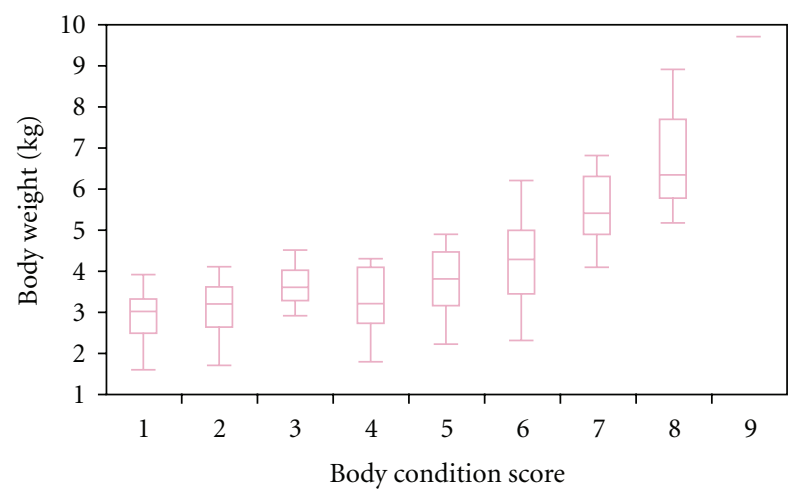

FIGURE 2: Distributions of raccoon body weight for each body condition score category (BCS 1-9), displaying median, quartiles, minimum, and maximum values.

$2-3 \mathrm{~cm}$ caudal to the umbilicus with the long axis of the transducer placed parallel to the vertebral column. The time required to obtain each ruler and ultrasound measurement was recorded to the nearest second using a stopwatch, starting when the incision was made or the probe was placed on the skin, respectively, and stopping when the measurement was successfully recorded. The sum was then calculated for each animal to obtain a collective ultrasound measurement time and collective ruler measurement time.

Followup studies were conducted during two necropsy sessions on subsets of 149 raccoons collected from the Outer Banks of North Carolina. This population was sampled as part of an experimental removal conducted on a North Carolina barrier island under North Carolina State University I.A.C.U.C. approval (no. 07- 0120-0). Raccoons were live trapped, anesthetized with Tiletamine $\mathrm{HCl}$ and Zolazepam $\mathrm{HCl}(10 \mathrm{mg} / \mathrm{kg} \mathrm{IM}$, Telazol, Fort Dodge Animal Health, Fort Dodge, IA 50501, USA), and then euthanized using an intravenous or intracardiac injection of pentobarbital sodium ( $1 \mathrm{~mL} / 4.5 \mathrm{~kg}$, Beuthanasia, Schering-Plough Animal Health, Omaha, NE 68138, USA). Carcasses were frozen, transported to College of Veterinary Medicine at North Carolina State University, and thawed for necropsy analysis.

One veterinarian with expertise in estimating body condition scores in nondomestic species performed all body condition scoring to eliminate interobserver variation. Body condition scores were based on a 9-point scale, with a score of 5 considered the ideal fit body condition. Because the dense hair coat prevented evaluation of body contours, palpation was used to assess the relative amount of subcutaneous fat over the vertebral column, ribs, and pelvic bones. Body condition scores, weight, and sex were recorded for all 149 animals.

In a subset of 65 raccoons, ultrasound measurements were conducted as previously described. In another subset of 18 raccoons, dissected physical measurements of subcutaneous fat depth were conducted as previously described. Three animals per BCS category 1-6 were used for this latter dataset.

Statistical analysis was performed using JMP 7.0 computer software (Cary, NC 27513, USA). Comparisons between body condition score, body weight, and measurement locations utilized nonparametric Spearman correlation coefficients. Comparison of the two techniques at each location used Wilcoxon signed rank. A value of $z<0.01$ was considered statistically significant.

\section{Results}

The eight animals in the pilot study included four males and four females. Body condition scores for this group ranged from 1 to 5, with no animals scored in the higher categories. Measuring fat with a ruler was faster than using ultrasound. Total time to obtain ultrasound measurements ranged from 127 to 181 seconds, with a mean of 146 seconds. Total dissected physical measurement time ranged from 44 to 84 seconds, with a mean of 59 seconds.

In the pilot study, interscapular, thoracolumbar, and ventral midline measurements between the two techniques were not significantly different $(z$ value $>0.01)$. This indicates that ultrasound at these three locations does accurately measure fat depth. Lumbosacral measurements were statistically significantly different $(z$ value $=0.0078)$ between the two techniques, but all measurements from all sites were within $2 \mathrm{~mm}$ of the opposing technique's value. When there were differences, ultrasound measurements were usually slightly thicker than those obtained with the ruler. Table 1 shows the median measurements obtained in the pilot study using both techniques at each location.

In the followup studies, 97 males $(65 \%)$ and 52 females (35\%) were examined. Body weight ranged from $1.2 \mathrm{~kg}$ to $9.7 \mathrm{~kg}$, with a mean of $3.9 \mathrm{~kg}$. Animals from all $9 \mathrm{BCS}$ categories were represented in this dataset. Body weight was strongly positively correlated with body condition score (Spearman $\rho$ 0.7006, $P<.0001$ ). Distributions of body weight for each body condition score category are illustrated in Figure 2.

For the subset of 65 animals measured with ultrasound, all four ultrasound sites were significantly correlated to body condition score $(P<.0001)$ and to body weight $(P<.001)$. Of the four locations, ventral midline had the strongest correlation to both body condition score and body weight. Table 2 shows the median ultrasound measurements for each location by body condition score category.

For the subset of 18 animals measured using dissected physical measurements, the thoracolumbar site was the only site not significantly correlated to body condition score 
TABLE 2: Medians and 10th to 90th percentiles (in $\mathrm{cm}$ ) for ultrasound fat depth measurements by site and body condition score category (BCS 1-9) (total $n=65)$.

\begin{tabular}{|c|c|c|c|c|c|c|c|c|}
\hline \multirow[t]{2}{*}{ BCS } & \multicolumn{2}{|c|}{ Interscapular } & \multicolumn{2}{|c|}{ Thoracolumbar } & \multicolumn{2}{|c|}{ Lumbosacral } & \multicolumn{2}{|c|}{ Ventral midline } \\
\hline & Median & 10th-90th & Median & 10th-90th & Median & 10th-90th & Median & 10th-90th \\
\hline $1(n=1)$ & 0.14 & - & 0.14 & - & 0.14 & - & 0.12 & - \\
\hline $2(n=2)$ & 0.21 & $0.16-0.26$ & 0.18 & $0.12-0.24$ & 0.17 & $0.16-0.18$ & 0.11 & $0.1-0.12$ \\
\hline $3(n=8)$ & 0.29 & $0.22-0.42$ & 0.30 & $0.22-0.53$ & 0.28 & $0.2-0.41$ & 0.18 & $0.16-0.43$ \\
\hline $4(n=5)$ & 0.34 & $0.22-0.65$ & 0.34 & $0.26-0.57$ & 0.28 & $0.24-0.85$ & 0.18 & $0.16-0.26$ \\
\hline $5(n=8)$ & 0.3 & $0.22-0.61$ & 0.37 & $0.26-0.53$ & 0.36 & $0.26-0.52$ & 0.2 & $0.12-0.26$ \\
\hline $6(n=17)$ & 0.32 & $0.25-0.46$ & 0.38 & $0.32-0.49$ & 0.41 & $0.26-0.57$ & 0.22 & $0.16-0.32$ \\
\hline $7(n=16)$ & 0.37 & $0.26-0.5$ & 0.4 & $0.31-0.7$ & 0.48 & $0.34-0.68$ & 0.3 & $0.23-0.49$ \\
\hline $8(n=7)$ & 0.41 & $0.34-0.61$ & 0.45 & $0.38-0.83$ & 0.51 & $0.41-0.67$ & 0.41 & $0.24-1.03$ \\
\hline $9(n=1)$ & 0.43 & - & 0.61 & - & 0.75 & - & 0.69 & - \\
\hline
\end{tabular}

TABle 3: Medians and 10th to 90th percentiles (in $\mathrm{cm}$ ) for dissected physical fat depth measurements by site and body condition score category (BCS 1-6) (total $n=18)$.

\begin{tabular}{lcccccccc}
\hline BCS & \multicolumn{2}{c}{ Interscapular } & \multicolumn{2}{c}{ Thoracolumbar } & \multicolumn{2}{c}{ Lumbosacral } & \multicolumn{2}{c}{ Ventral midline } \\
& Median & 10th-90th & Median & 10th-90th & Median & 10th-90th & Median & 10th-90th \\
\hline $1(n=3)$ & 0.2 & $0.1-0.3$ & 0.1 & $0.1-0.2$ & 0.1 & $0.1-0.1$ & 0.2 & $0.2-0.2$ \\
$2(n=3)$ & 0.2 & $0.2-0.2$ & 0.2 & $0.1-0.2$ & 0.1 & $0.1-0.2$ & 0.2 & $0.2-0.2$ \\
$3(n=3)$ & 0.3 & $0.3-0.5$ & 0.2 & $0.2-0.3$ & 0.2 & $0.2-0.3$ & 0.3 & $0.2-0.3$ \\
$4(n=3)$ & 0.4 & $0.3-0.4$ & 0.3 & $0.2-0.3$ & 0.3 & $0.3-0.3$ & 0.4 & $0.3-0.5$ \\
$5(n=3)$ & 0.3 & $0.3-0.4$ & 0.3 & $0.2-0.3$ & 0.3 & $0.3-0.4$ & 0.4 & $0.2-0.8$ \\
$6(n=3)$ & 0.4 & $0.4-0.5$ & 0.2 & $0.2-0.3$ & 0.3 & $0.3-0.3$ & 0.4 & $0.3-0.5$ \\
\hline
\end{tabular}

(Spearman $\rho$ 0.571, $P$-value $=.0123)$. Table 3 shows the median dissected physical measurements for each location by body condition score category.

\section{Discussion}

The ideal method of measuring body condition should be rapid, noninvasive, accurate, and economical and requires minimal training [3]. Ultrasound meets several of these criteria, with the limitations that the capital investment in ultrasound equipment is expensive, and training and practice is required to use it effectively [28]. The ultrasound machine used during this investigation is portable, durable and could be used in the field during routine examinations. The noninvasive nature of the technique makes ultrasound an appealing method for estimating body condition in live animals.

Body condition scoring is a less expensive alternative to ultrasonography. However, due to its inherent subjectivity, personnel must be trained for each species evaluated to optimize the value of the assessments and to minimize interobserver variation [28]. Body condition scoring done by an experienced person can, however, be a useful guide to the nutritional status of an animal or group of animals [21], and in this study, body condition scores were well correlated to both body weight and ultrasound and ruler fat depth measurements. The use of a single individual with experience performing all body condition scores certainly contributed to this result. With practice, researchers and clinicians could use this tool for diagnostic, prognostic, and monitoring purposes.

In this study, the time required to measure fat with ultrasound was slightly longer than the time it took to measure fat by dissected physical measurement. When using ultrasound, tissue layers (e.g., skin, fat, and muscle) are readily evident, but measurement with the electronic calipers took more time in the hands of our ultrasonographer than recording the ruler measurement with pen to a preprepared data sheet. Despite this, the technique did not take much longer and is easy to learn, and being noninvasive makes it preferable for survival studies.

Comparing the two quantitative measurement methods (ultrasound and dissected physical measurement), the interscapular, thoracolumbar, and ventral midline values were not significantly different between methods. This suggests that ultrasound has similar accuracy to dissected physical measurement of fat depth in these locations. The lumbosacral paraspinal location did not have as good agreement between the two methods. This may have been a result of the difficulty placing the ultrasound probe between the coxal tuber and ischial tuber in some of the smaller individuals, where reflections from boney prominences made obtaining an ultrasound image difficult.

Fat layer thickness at all four locations measured within $2 \mathrm{~mm}$ of the opposing technique's measurement, even for the lumbosacral location. When there was a difference, ultrasound routinely returned slightly thicker measurements than those obtained with the ruler. This is perhaps due to 
the ultrasound machine measuring to the nearest $0.01 \mathrm{~cm}$, while physical measurements were only taken to the nearest millimeter. The relatively minor differences observed, though statistically significant for the lumbosacral measurement, do not appear to be of a scale that would be considered clinically significant when one looks at the relationship with body condition scores. The consistency of the direction of variation suggests that either technique could be used and potentially reconciled with the other between studies once more extensive comparative datasets are available.

Ultrasound measurements of fat at all four sites were significantly correlated to both body condition score and body weight, with the ventral midline measurement having the strongest correlations. The ventral midline site is also easy to access, even in small individuals, and should be considered the best location for ultrasonic fat measurement to establish body condition in raccoons. The design of our study did not examine repeatability nor were the examined cohorts balanced for body condition because of the skewed nature of our sample, with overconditioned animals underrepresented in the dataset.

Subdermal fat accounts for $96 \%$ of fat in raccoons, whereas abdominal fat accounts for only 4\% [5]. Also, adult raccoons can lose up to $50 \%$ of their body weight each year during colder weather and then metabolize those fat reserves [33]. These factors make the raccoon an ideal candidate for using subcutaneous fat measurements to assess body condition. This study validated ultrasound of body fat as an accurate means of assessing body condition in raccoons. This technique is likely applicable to other mammalian species and should be considered for use, in conjunction with body condition score and body weight, when evaluating the nutritional status of small carnivores.

\section{Acknowledgments}

The authors thank Andrew Moore of USDA-APHIS for provision of the pilot study specimens and the North Carolina State University veterinary students who assisted in the collection of data for this study.

\section{References}

[1] T. H. Yeen, S. Larivière, and F. Messier, "Evaluating body condition of striped skunks using non-invasive morphometric indices and bioelectrical impedance analysis," Wildlife Society Bulletin, vol. 33, no. 1, pp. 195-203, 2005.

[2] J. R. Speakman, "Introduction," in Body Composition Analysis of Animals. A Handbook of Non-Destructive Methods, J. R. Speakman, Ed., pp. 1-7, Cambridge University Press, Cambridge, UK, 2001.

[3] A. D. Mitchell and A. M. Scholz, "Techniques for measuring body composition of swine," in Swine Nutrition, A. J. Lewis and L. L. Southern, Eds., pp. 917-960, CRC Press, Boca Raton, Fla, USA, 2nd edition, 2001.

[4] D. S. Reynolds and T. H. Kunz, "Standard methods for destructive body composition analysis," in Body Composition Analysis of Animals. A Handbook of Non-Destructive Methods, J. R. Speakman, Ed., pp. 39-55, Cambridge University Press, Cambridge, UK, 2001.
[5] J. A. Pitt, S. Larivière, and F. Messier, "Condition indices and bioelectrical impedance analysis to predict body condition of small carnivores," Journal of Mammalogy, vol. 87, no. 4, pp. 717-722, 2006.

[6] P. Cavallini, "Comparison of body condition indices in the red fox (Fissipedia, Canidae)," Mammalia, vol. 60, no. 3, pp. 449462, 1996.

[7] L. A. Windberg, R. M. Engeman, and J. F. Bromaghin, "Body size and condition of coyotes in southern Texas," Journal of wildlife diseases, vol. 27, no. 1, pp. 47-52, 1991.

[8] J. P. Hayes and J. S. Shonkwiler, "Morphometric indicators of body condition: worthwhile or wishful thinking?" in Body Composition Analysis of Animals. A Handbook of NonDestructive Methods, J. R. Speakman, Ed., pp. 8-38, Cambridge University Press, Cambridge, UK, 2001.

[9] C. J. Krebs and G. R. Singleton, "Indices of condition for small mammals," Australian Journal of Zoology, vol. 41, no. 4, pp. 317-323, 1993.

[10] J. A. Virgl and F. Messier, "Evaluation of body size and body condition indices in muskrats," Journal of Wildlife Management, vol. 57, no. 4, pp. 854-860, 1993.

[11] I. Scott, C. Selman, P. I. Mitchell, and P. R. Evans, "The use of total body electrical conductivity (TOBEC) to determine body composition in vertebrates," in Body Composition Analysis of Animals. A Handbook of Non-Destructive Methods, J. R. Speakman, Ed., pp. 127-160, Cambridge University Press, Cambridge, UK, 2001.

[12] W. D. Van Marken Lichtenbelt, "The use of bioelectrical impedance analysis (BIA) for estimation of body composition," in Body Composition Analysis of Animals. A Handbook of Non-Destructive Methods, J. R. Speakman, Ed., pp. 161-187, Cambridge University Press, Cambridge, UK, 2001.

[13] W. D. Bowen, C. A. Beck, and S. J. Iverson, "Bioelectrical impedance analysis as a means of estimating total body water in grey seals," Canadian Journal of Zoology, vol. 77, no. 3, pp. 418-422, 1999.

[14] G. Castro, B. A. Wunder, and F. L. Knopf, "Total Body Electrical Conductivity (TOBEC) to estimate total body fat of free-living birds," The Condor, vol. 92, no. 2, pp. 496-499, 1990.

[15] D. D. Roby, "A comparison of two noninvasive techniques to measure total body lipid in live birds," The Auk, vol. 108, no. 3, pp. 509-518, 1991.

[16] L. Fortun-Lamothe, B. Lamboley-Gaüzère, and C. Bannelier, "Prediction of body composition in rabbit females using total body electrical conductivity (TOBEC)," Livestock Production Science, vol. 78, no. 2, pp. 133-142, 2002.

[17] A. J. Wirsing, T. D. Steury, and D. L. Murray, "Noninvasive estimation of body composition in small mammals: a comparison of conductive and morphometric techniques," Physiological and Biochemical Zoology, vol. 75, no. 5, pp. 489497, 2002.

[18] R. C. Cook, J. G. Cook, D. L. Murray, P. Zager, B. K. Johnson, and M. W. Gratson, "Development of predictive models of nutritional condition for Rocky Mountain elk," Journal of Wildlife Management, vol. 65, no. 4, pp. 973-987, 2001.

[19] G. V. Hilderbrand, S. D. Farley, and C. T. Robbins, "Predicting body condition of bears via two field methods," Journal of Wildlife Management, vol. 62, no. 1, pp. 406-409, 1998.

[20] K. L. Otto, J. D. Ferguson, D. G. Fox, and C. J. Sniffen, "Relationship between body condition score and composition of ninth to eleventh rib tissue in Holstein dairy cows," Journal of Dairy Science, vol. 74, no. 3, pp. 852-859, 1991. 
[21] W. J. Burkholder, "Use of body condition scores in clinical assessment of the provision of optimal nutrition," Journal of the American Veterinary Medical Association, vol. 217, no. 5, pp. 650-654, 2000.

[22] U. J. Schröder and R. Staufenbiel, "Invited review: methods to determine body fat reserves in the dairy cow with special regard to ultrasonographic measurement of backfat thickness," Journal of Dairy Science, vol. 89, no. 1, pp. 1-14, 2006.

[23] A. M. Hynes, K. Rouvinen-Watt, and D. Armstrong, "Body condition and glycemic control in mink females during reproduction and lactation," Scientifur, vol. 28, no. 3, pp. 7986, 2004.

[24] K. L. Gerhart, R. G. White, R. D. Cameron, and D. E. Russell, "Estimating fat content of caribou from body condition scores," Journal of Wildlife Management, vol. 60, no. 4, pp. 713$718,1996$.

[25] A. D. Mitchell, "Impact of research with cattle, pigs, and sheep on nutritional concepts: body composition and growth," Journal of Nutrition, vol. 137, no. 3, pp. 711-714, 2007.

[26] J. J. Domecq, A. L. Skidmore, J. W. Lloyd, and J. B. Kaneene, "Validation of body condition scores with ultrasound measurements of subcutaneous fat of dairy cows," Journal of dairy science, vol. 78, no. 10, pp. 2308-2313, 1995.

[27] T. R. Stephenson, K. J. Hundertmark, C. C. Schwartz, and V. Van Ballenberghe, "Predicting body fat and body mass in moose with ultrasonography," Canadian Journal of Zoology, vol. 76, no. 4, pp. 717-722, 1998.

[28] C. J. Bishop, B. E. Watkins, L. L. Wolfe, D. J. Freddy, and G. C. White, "Evaluating mule deer body condition using serum thyroid hormone concentrations," Journal of Wildlife Management, vol. 73, no. 3, pp. 462-467, 2009.

[29] D. D. Gustine, K. L. Parker, and D. C. Heard, "Using ultrasound measurements of rump fat to assess nutritional condition of woodland caribou in northern British Columbia, Canada," Rangifer, no. 17, pp. 249-256, 2007.

[30] N. J. Gales and H. R. Burton, "Ultrasonic measurement of blubber thickness of the southern elephant seal, Mirounga leonina (Linn)," Australian Journal of Zoology, vol. 35, pp. 207 $217,1987$.

[31] A. J. Hall and B. J. McConnell, "Measuring changes in juvenile gray seal body composition," Marine Mammal Science, vol. 23, no. 3, pp. 650-665, 2007.

[32] J.-A. E. Mellish, P. A. Tuomi, and M. Horning, "Assessment of ultrasound imaging as a noninvasive measure of blubber thickness in pinnipeds," Journal of Zoo and Wildlife Medicine, vol. 35, no. 1, pp. 116-118, 2004.

[33] S. D. Gehrt, "Raccoons (Procyon lotor and allies)," in Wild Mammals of North America: Biology, Management, and Conservation, G. A. Feldhammer, B. C. Thompson, and J. A. Chapman, Eds., pp. 611-634, John Hopkins University Press, Baltimore, Md, USA, 2nd edition, 2003. 

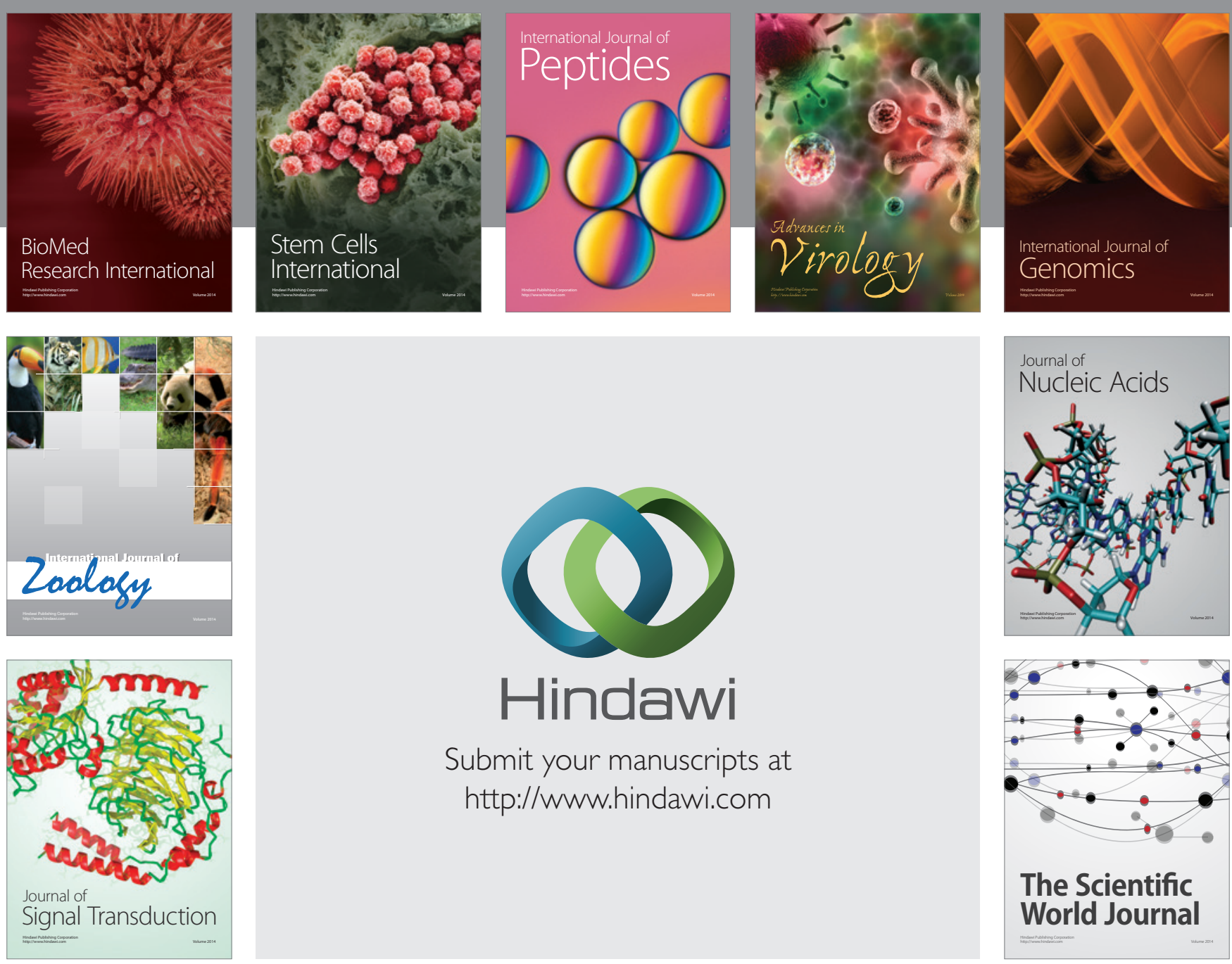

Submit your manuscripts at

http://www.hindawi.com
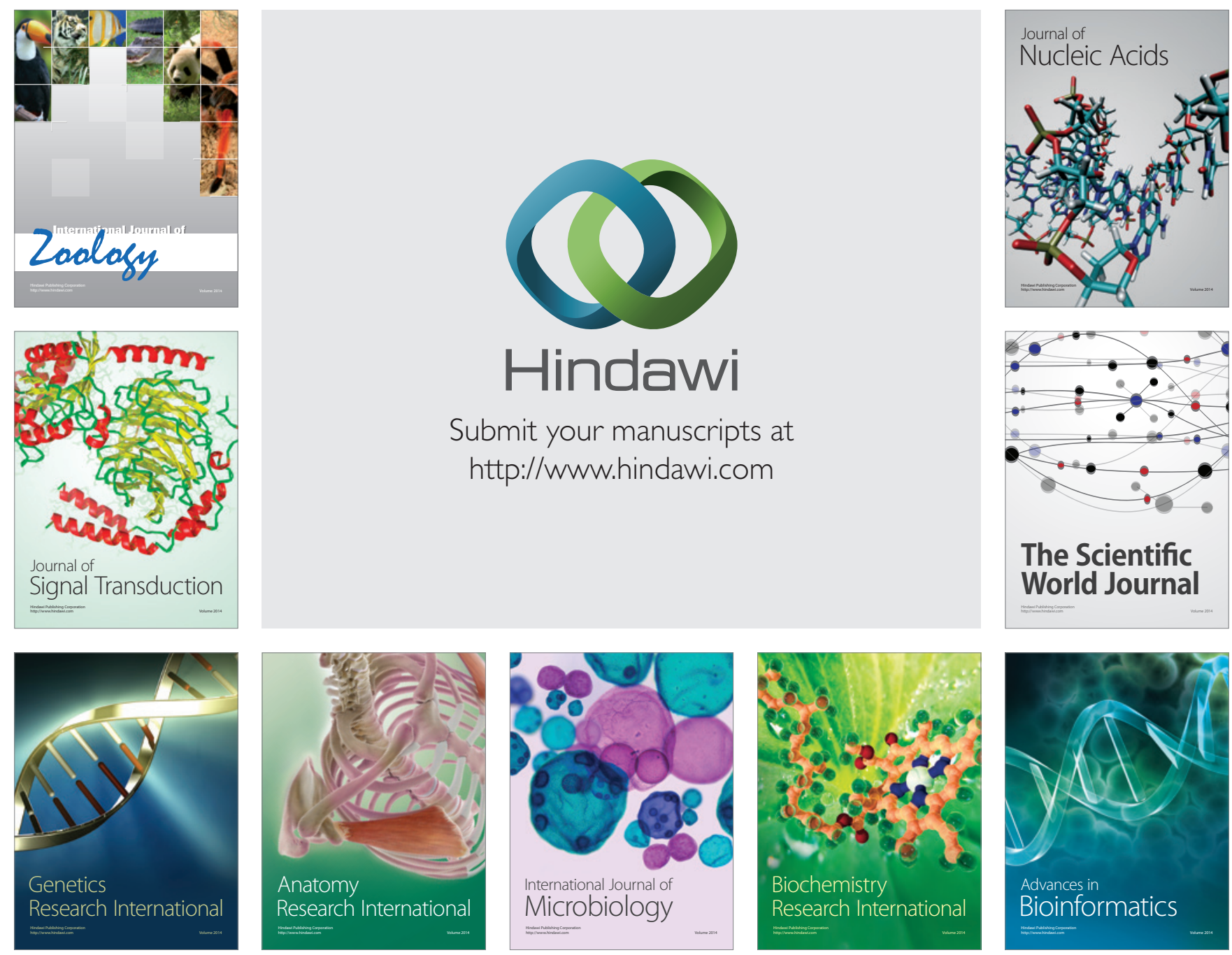

The Scientific World Journal
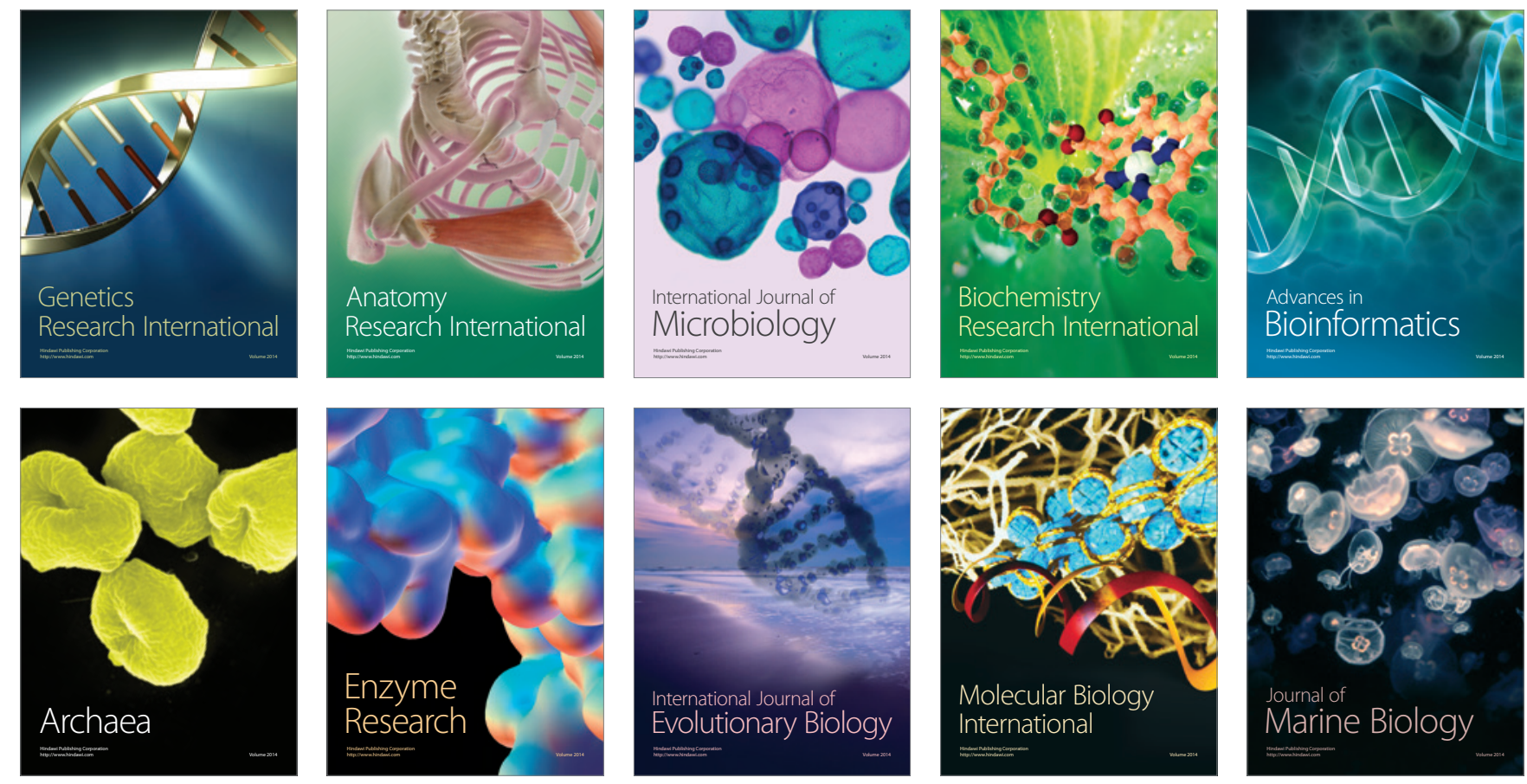